THURSDAY, MAY 26, 1870

\section{THE NEW NATURAL HISTORY MUSEUM}

WITHIN the last few days two members of Her Majesty's Government, the Chancellor of the Exchequer and the Premier himself, have declared, in their places in Parliament, that it is the wish and intention of the Ministry to carry into effect, without further delay, the long-talked-of project of erecting a special building to contain the Natural History Collections of the British Museum.

That this announcement will be received with great satisfaction by the large body of persons interested in the various branches of natural history in this country there can be no doubt, although there may be misgivings in some quarters lest the fullest advantage should not be taken of so grand an opportunity of making the very best museum of the kind in the world. These misgivings are in a great measure justified by the present condition of not only our own, but nearly all other European Zoological Museums, and more especially by the plans that have at various times been put forth in a semi-official manner, as representing the ideal of what such a museum should be.

Long and extensive experience has, or ought to have, taught us the best principle of construction as applied to libraries and picture galleries; but the natural history sciences are in their infancy as compared with literature and art, and the best methods by which their treasures can be housed and exhibited have yet to be learned. The way in which this is done in the new Museum will exercise so great an influence upon the progress of these sciences, that it should not be determined upon without full consideration by those who are most conversant with their present state, and with the probable wants of a future generation of students.

Let the reader imagine what a public library would be if the books, instead of being shut up and arranged on the shelves for consultation when required, had every single page framed and glazed and hung on the wall, so that the humblest visitor as he passes along the galleries has only to open his eyes and revel in the wealth of literature of all ages and all countries, without so much as applying to a custodian or opening a case. There is something truly heroic in the conception of such a scheme ; but laying aside all questions of space and cost, what would be its real utility to those who are able to appreciate and make true use of its contents! All the inconveniences, all the impossibilities, I may say, of a library arranged upon such a plan would be found in a museum containing anything like an adequate number of objects for the purposes of really enlarging the boundaries of scientific zoology, in which every specimen contained in it were exposed to the gaze of all who choose to enter its walls.

We are only beginning to form any idea of the enormous numbers of specimens actually required to enable us to rest our generalisations relating to most zoological problems upon a firm basis, and of the importance of keeping these specimens in such a condition, and so placed, that they can be examined and compared with the greatest facility. Provision should, therefore, be made in the new

VOL. II.
Museum for the great bulk of the collection being thus treated. It would be quite a mistake to suppose that they would then be shut up and put away, and that the public have no further concern in them, and ought not to be expected to pay for their accommodation. They would be in exactly the same circumstances as the books in a wellarranged library, and ought to be equally accessible under suitable regulations; and there are thousands of people who will read with interest the conclusions that scientific men will draw from their study of them, who would never care to see, or if they did, never learn anything from, the specimens thenselves.

At the same time, the other essential function of a Natural History Museum, the diffusion of knowledge among the general public, should be carefully provided for, and means should be taken by which these two objects may be carried on simultaneously, and, at all times, without interfering with each other, instead of continuing the present excessively inconvenient system of alternate closed and open days. This, and many other advantages, upon which I need not dwell at present, can be readily secured by the admirable plan, first suggested, I believe, by Mr. Sclater, of having all the glass-cases hermetically closed on the side towards the public galleries, and opening behind into the working-rooms in which the unexhibited portions of the same series are arranged in drawers or cabinets. In this way, any exhibited specimen, if required for examination or comparison, could be readily removed and replaced, without inconvenience to the visitors, and without letting in the dust which necessarily fills the air of the crowded public galleries. One of the principal objections to lighting the Museum with gas in the evening would also be obviated if this were carried out.

Another important requirement in the arrangement of a new Museum of Natural History is the abolition of the special department of palæontology. There might be a comparatively small geological series, consisting of characteristic fossils arranged stratigraphically, but the great bulk of extinct animals should be incorporated with the zoological series, so that they may be studied side by side with their existing representatives, not only by the sight-seeing public and specially-instructed visitors, but also by those who have charge of the collections. If the construction of the new museum tends to perpetuate the present artificial distinction between extinct and recent species of animals, it will hinder instead of promoting the progress of any general conception of the organic world as a whole, and will also impose unnecessary difficulties in working out the minute comparisons by which the affinities and gradations between the various units of which that world is composed are recognised.

It would probably be premature at the present time to enter into any further discussion of details, since the subject has so often seemed nearly as far advanced as now, and has as often receded again into the far-off distance. But after the declaration of last Friday evening it should be in a fairerway of being realised than ever before it, and it behoves the working naturalists of the country to lend their aid in furthering the excellent intentions of the Government by making known their well-considered opinions upon this most important question.

\section{W. H. FLOWER}

